\title{
INTERNET: FATOR DE INCLUSÄO DA PESSOA SURDA
}

\section{Andréa da Silva Rosa Cristiano Cordeiro Cruz}

RESUMO: Neste trabalho são descritos alguns dos vários tipos de uso que um surdo pode fazer da Internet. Para tal iniciamos com uma apresentação resumida sobre a história da Internet, seguida por um panorama geral sobre a condição de vida dos surdos ao longo da história da humanidade até os dias de hoje. Com base nisso, são apresentados vários recursos que a Internet pode oferecer aos surdos, no sentido de potencializar-lhes independência e melhor acesso à informação/ comunicação. Também são discutidas algumas novas potencialidades que ela pode prover a esta parte da população em um futuro próximo, através da sua evolução técnica e do surgimento e desenvolvimento de outras tecnologias.

PALAVRAS-CHAVE: Surdo, Internet, Inclusão, Tecnologia.

\begin{abstract}
In this paper we describe some kinds of useful Internet applications related to deaf people. In the first section we present some outlines on Internet evolution, followed by a general overview of deaf people life conditions throughout history of mankind, shown in the second section. With this in mind, in the third section we present various means by which Internet may offer deaf people the possibility of independence and better access to information/ communication tools. Finally, in the last section we deal with some new Internet applications, based on emergent technologies, which may enhance deaf people quality of life.
\end{abstract}

KEY-WORDS: Deaf people, Internet, Inclusion, Technology.

\footnotetext{
${ }^{1}$ Os testemunhos de Patricia Hipolito de Alexandria Silva Nunes e Regiane Pinheiro Agrella, surdas, por ocasião da primeira apresentação deste trabalho (Faculdade de Educação da Unicamp, 08/agosto/2000), foram extremamente importantes para a reformulação do mesmo. A íntegra destes escritos pode ser acessada através do endereço: http://www.decom.fee.unicamp.br/ cristia/surdos/intro.html.
} 


\section{INTRODUÇÃO}

O homem que chega ao novo milênio é de uma técnica e de um conhecimento científico tamanhos, nunca outrora verificados. No entanto, a sua moral e os seus valores se não se deterioraram, ao menos não evoluíram na mesma velocidade.

Dentro deste contexto amplo, as questões da vida e do reconhecimento da dignidade dos surdos ainda estão muito aquém de qualquer parâmetro eticamente estabelecido. É bem verdade que já não temos mais os assassinatos de antes, mas este processo de melhora na qualidade de vida dos surdos ainda está no seu início.

O movimento que se tem percebido nos últimos tempos por parte daqueles que verdadeiramente se importam com os surdos, é de ajudá-los a se capacitarem no sentido de eles próprios tomarem as decisões que lhes dizem respeito. E isso nada mais é do que tirar da teoria a ética que o ocidente diz professar, que prevê como inalienável ao homem o direito à vida e à liberdade para buscar bem vivê-la a seu modo.

Neste sentido, a Internet surge como mais uma ferramenta que potencializa ao surdo analisar a realidade com menos "intermediários" do que antes, conferindo a ela os julgamentos que lhes parecem pertinentes (ao invés de recebê-los prontos de outrém). O próprio surdo pode interagir com a informação que, diferentemente das outras mídias tradicionais, pode ter agregada ao texto, figuras e "efeitos visuais" que podem facilitar o seu entendimento. Além disso, a escrita em sinais e a possibilidade de veiculação de informações em língua de sinais gestual, são grandes atrativos e promessas que a Internet pode oferecer.
No entanto, como afirma Laurillard (1996), é um absurdo tentar resolver o problema da educação dando às pessoas acesso à informação, da mesma forma como seria absurdo tentar solucionar o problema de habitação dando às pessoas acesso aos tijolos. Ou seja, apesar de ter um meio potencialmente melhor aplicável ao surdo, não é ele que irá "formá-lo". Isso porque para que se consiga interpretar "adequadamente" a realidade e interagir através da Internet, não basta ter acesso a ela, mas saber usá-la. E isso é algo se aprende/ ensina, mas que muitas vezes não se sabe como...

Este trabalho está dividido em três seções principais: na primeira é explicada sucintamente a história da Internet, apresentando-se os principais marcos na sua evolução; na segunda é traçado um breve resumo histórico sobre a vida dos surdos na humanidade, destacando-se algumas conquistas importantes no cenário nacional das últimas décadas; por fim, na terceira seção, são descritas algumas potencialidades da Internet para o uso com a pessoa surda, bem como são traçados alguns horizontes para o seu uso com o surdo em um futuro próximo.

\section{A HISTÓRIA DA INTERNET}

$\mathrm{O}$ advento da Internet é algo bem recente e está intimamente relacionado com o desenvolvimento dos computadores. Desta forma, antes de explicar a história da Internet, faremos um breve resumo sobre a história do computador.

Computador significa, segundo os dicionários, aquele que faz contas. $\mathrm{E}$ os primeiros artefatos que surgiram com esse nome faziam jus a ele, como os ábacos, os primeiros computadores de que se tem 
notícia, cuja origem remonta há 5000 anos. Os ábacos eram máquinas que permitiam contas de somar, subtrair, multiplicar e dividir. No entanto, o seu manuseio não era fácil, e requeria uma certa técnica.

A partir do século XVII são inventados os primeiros computadores mecânicos. Estes computadores eram um conjunto de engrenagens que, a princípio, só permitiam contas de somar e subtrair. Uma das várias diferenças entre estes computadores (chamados de máquinas de calcular) e os ábacos, era que, nestes, o homem precisava operar o aparelho, e interpretar o seu resultado. Já no caso das máquinas de calcular, eram inseridos dois números, e a máquina retornava um terceiro, que era o resultado da operação desejada. Assim, não se tinha mais que interpretar os resultados, pois eles já eram dados prontos.

A evolução do computador eletrônico como conhecemos hoje, só se inicia com a II Guerra Mundial. Foi nesta guerra que os computadores começaram a demonstrar o seu grande potencial estratégico, de modo que os governos começaram a se interessar bastante neles, para fins militares.

A partir daí, as evoluções aconteceram em ritmo acelerado: com a invenção da microeletrônica (os semicondutores, os transistores,...) permitiu-se a miniaturização do computador, possibilitando-se um barateamento no seu custo e uma diminuição no seu consumo; com a elaboração de programas de computador mais fáceis para o entendimento do homem que permitiram um uso mais amigável e menos complicado destes artefatos; com a invenção dos sistemas operacionais que conferiram facilidade e flexibilidade no seu uso, uma vez que diversos programas passam a poder estar ativos ao mesmo tempo; e com a invenção dos PC (Personal
Computers - Computadores Pessoais) que consolidou a popularização destas máquinas, permitindo que um usuário pudesse comprá-la e instalá-la em sua própria residência. Com isso, os computadores passam a não ser só artigo de universidades e do governo, mas todas as pessoas já podem ter e manipular um.

É no meio desta (r)evolução surge a Internet, no final da década de 60. A idéia que se tinha era de se permitir a comunicação entre vários computadores distantes, de modo a se poder trocar informações de maneira segura e rápida. Por trás disso havia dois tipos de interesses: militarmente falando, o contexto histórico que se vivia era o da Guerra Fria. Assim, para os Estados Unidos (local em que a Internet começou a ser desenvolvida) era muito importante que houvesse um confiável sistema de trocas de informação, e que não sucumbisse caso algum dos centros de computadores fossem atingidos por um ataque nuclear soviético. Em termos acadêmicos, esta troca de informações rápida e segura era de extremo interesse da comunidade científica, que via nisso um grande potencial para o desenvolvimento de pesquisas e trabalhos.

Hoje, a Internet já é realidade em boa parte do mundo, e não mais se restringe ao uso acadêmico ou militar. Ela, juntamente com a rede WWW, permite que se possa fazer pelo computador, várias coisas que, antes, era preciso fazer pessoalmente. Neste sentido, hoje, pode-se fazer compras, ler jornais, consultar bibliotecas, conversar com amigos,..., tudo através do computador, sem sair de casa (ou do trabalho). Isso, aliado ao grande potencial que a Internet tem para prover a comunicação e o acesso rápido a informações a tornam algo altamente importante e estratégico para o mundo do novo século. 


\section{A HISTÓRIA DO SURDO}

Desde o início da humanidade, todas as pessoas que não eram iguais à maioria eram discriminadas. Com os surdos, não foi diferente. Eles foram vítimas de preconceitos, e quase sempre foram muito marginalizados, rejeitados e perseguidos.

Cada diferença tem suas características próprias e provoca conseqüências particulares. Uma pessoa cega fica isolada do mundo das coisas, ou seja, do mundo dos objetos e das formas. Assim, para um cego, não faz sentido falar-se em claro ou escuro, imagem bonita ou feia, mar azul ou verde.

Já no caso do surdo, as imagens são o seu mundo. $\mathrm{O}$ surdo não fica isolado do mundo das coisas, do mundo visual. O surdo fica isolado do mundo dos homens, do mundo da conversa, do mundo do diálogo verbal. O surdo consegue fazer uma leitura do mundo, mas o surdo não consegue ouvir o homem, e o homem (normatizante) não consegue ouvir o surdo.

Segundo Oliver Sack, a surdez em si não é o infortúnio; o infortúnio sobrevém com o colapso da comunicação e da linguagem (1989, p 130).

Por não dialogar oralmente, os surdos sempre foram incompreendidos na sua humanidade. As pessoas não entendiam o que os surdos queriam e, diversas vezes, tomaram decisões por eles que, longe de trazer algum benefício, só ajudaram a dificultar ainda mais a sua situação no mundo.

Ao longo da história, e das diversas culturas, os surdos foram considerados desde pessoas imprestáveis e amaldiçoadas, até pobre coitados que deveriam ser sempre tutelados, e que não poderiam jamais ter vida própria (por não serem considerados capazes de geri-la).

A forma com eu se lidava com eles neste período, variou desde a selvageria do extermínio "legalizado" (através de infanticídio), até um cuidado mais sério, mas que, no entanto, nunca conseguiu ser bom o suficiente para estimulá-lo e inserilo na sociedade.

A partir do século XVI surgem os primeiros pedagogos para surdos, e a sua educação e inclusão na sociedade começam a ser repensadas de forma séria. Houve vários progressos e retrocessos (controversos) neste período todo. Hoje, com todas as limitações e controvérsias, chega-se ao limiar do século XXI, com uma situação menos bárbara que dos primeiros assassinatos de bebês, mas que ainda está longe de ser algo realmente dignificante. $\mathrm{O}$ surdo ainda não consegue ser compreendido, nem tratado como ser humano, diferente não deficiente. E este desafio nós trazemos para o próximo século: como inscrever o surdo, com diferenças lingüísticas, na nossa sociedade produtivista, competitiva e excludente?

\section{PEQUENO HISTÓRICO DOS ÚLTIMOS 23 ANOS NO BRASIL}

- 1977 - Criado no Rio de Janeiro a Federação Nacional de Educação e Integração dos Deficientes Auditivos, FENEIDA, com diretoria de ouvintes.

- Final da década de 70 - Introduzida a Comunicação Total no Brasil sob a influência do Congresso Internacional da Gallaudet.

- 1981 - Início das pesquisas sistematizadas sobre a Língua de Sinais no Brasil.

- 1982 - Elaboração em equipe de um projeto subsidiado pela ANPOCS e 
pelo CNPQ intitulado "Levantamento lingüístico da Língua de Sinais dos Centros Urbanos Brasileiros (LSCB) e sua aplicação na educação". A partir desta data, diversos estudos lingüísticos sobre LIBRAS são efetuados sobre a orientação da lingüista L. Brito, principalmente na UFRJ. A problemática da surdez passa a ser alvo de estudos para diversas Dissertações de Mestrado.

- 1983 - Criação no Brasil da Comissão de Luta pelos Direitos dos Surdos.

- 1987 - Criação da Federação Nacional de Educação e Integração dos Surdos (FENEIS), em 16/05/87, sob a direção de surdos.

- 1991 - A LIBRAS é reconhecida oficialmente pelo Governo do Estado de Minas Gerais (lei $\mathrm{n}^{\mathrm{o}} 10.397$ de 10/1/91).

- 1994 - Começa a ser exibido na TV Educativa o programa VEJO VOZES (out/94 a fev/95), usando a Língua de Sinais Brasileira.

- 1995 - Criado por surdos no Rio de Janeiro o Comitê Pró-Oficialização da Língua de Sinais.

- 1996- São iniciadas, no INES, em convênio com a Universidade do Estado do Rio de Janeiro (UERJ), pesquisas que envolvem a implantação da abordagem educacional com Bilingüismo em turmas da pré-escola, sob a coordenação da lingüista $E$. Fernandes.

- 1998 - TELERJ - do Rio de janeiro, em parceria com a FENEIS, inaugurou a Central de atendimento ao surdo através do número 1402, o surdo em seu TS, pode se comunicar com o ouvinte em telefone convencional.

- 1999- Em março, começam a ser instaladas em todo Brasil telessalas com o telecurso 2000 legendado.

- 2000 - Após três anos de funcionamento no Jornal Nacional é disponibilizado o serviço de closed caption aos surdos também nos programas Fantástico, Bom Dia Brasil, Jornal Hoje, Jornal da Globo e programa do JÔ. É o fim da TV "muda".

Telefone celular para surdos: ATL.

Situação da Língua de Sinais no Brasil:

- Leis aprovadas em nível estadual: Minas Gerais, Goiás, Espírito Santo, Alagoas, Ceará, Rio Grande do Sul e Rio de Janeiro.

- Leis aprovadas em nível municipal: Recife, Caxias do Sul, Uberlância, Porto Alegre, Santa Maria, Joinville e Fortaleza.

- Em Minas Gerais (Lei $\mathrm{n}^{\circ}$ 13.623 , de 11 de julho de 2000), todas as mensagens publicitárias do governo, incluindo as campanhas eletorais, já têm obrigatoridade de exibirem legendas ou tradução para LIBRAS.

- O Projeto de Lei $\mathrm{n}^{\circ} 1.163$ de autoria do deputado Geraldo Resende, busca assegurar aos surdos $\mathrm{O}$ direito de serem atendidos nas repartições públicas estaduais de Minas Gerais em LIBRAS.

\section{O SURDO E A INTERNET}

\section{A QUESTÃO DA IGUALDADE}

No sentido da igualdade que não repara e não julga, a Internet tem se mostrado um local de profunda equidade entre todos os seus membros. Para isto, não se precisa ir 
muito longe, basta começar a navegar e a participar dos bate-papos virtuais, que se perceberá a multiplicidade e a diversidade de pessoas e informações que se pode encontrar na rede, sem, no entanto, haver qualquer tipo de preconceito ou discriminação.

Para os surdos, isto é inserção: é poder ser surdo, sem ser discriminado, ou sem ser excluído de um mundo sonoro. Nas palavras deles: A Internet, para os surdos, iguala todas as pessoas: pobres, ricos, surdos, ouvintes, brasileiros ou estrangeiros. (Luís Maurício Rigato Vasconcellos, Segundo Encontro Nacional de Surdos que se Conheceram na Internet São Paulo, 17/06/2000).

\section{INTERNET COMO FONTE DE INFORMAÇÃO E DE NOTÍCIAS}

Além desta potencialidade de trocas e de igualdade entre todos, a Internet é um grande "depósito" de dados e informações que podem servir para consultas e estudos (extra) curriculares de surdos e ouvintes. Esta vocação da rede WWW confere a ela uma característica semelhante a de uma "biblioteca" online: Nós podemos fazer pesquisa pela Internet, é ótimo (Regiane). Com isso, muitas vezes, a rede WWW pode servir de suporte ao surdo "incluído" em classe de aula de ouvintes. Neste caso, muitas vezes os surdos não conseguem acompanhar as aulas muito "faladas", como as de História, Filosofia, ... : Não consigo captar $90 \%$ da fala dos professores, por isso, leio muito e procuro entender o conteúdo das aulas nos livros e apostilas indicados. (Testemunho de Luíza Ferreira Pinto, surda desde 1 ano de idade, que atualmente cursa pedagogia. Esta entrevista foi dada à Revista do Ensino Superior, 03/2000, pg.16). Por conta disso, a Internet se torna uma fonte de apoio que potencializa a democratização dos saberes, já que pode prover material escrito (visual), que o surdo é capaz de ler, analisar e compreender.

Além de boa "provedora" deste tipo de material, a rede WWW é um excelente meio para se manter informado. Vários dos maiores jornais escritos do país possuem sites (como, por exemplo Estado de São Paulo, Folha de São Paulo, 0 Globo, Jornal do Brasil, Zero Hora (Porto Alegre). Estas informações, além de estarem, na sua grande maioria, na forma escrita (que pode ser entendida pelos surdos), estão sempre bastante atualizadas, substituindo, com grandes vantagens, o rádio e a televisão dos ouvintes.

Um cuidado, no entanto, que se deve tomar, é quanto à confiabilidade de notícias, dados e informações que circulam pela rede. Como não há nenhum controle sobre as páginas que são construídas e disponibilizadas, não se pode garantir que todas elas possuam informações relevantes e confiáveis. Por conta disso, se a Internet conecta surdos e ouvintes a um mundo extremamente grande de informações e conteúdos, ela também exige, para ser bem utilizada, um desenvolvido senso crítico por parte daqueles que nela navegam. Como muitos sabem, vários boatos já foram criados na rede e alguns deles foram relativamente bastante sérios. Um dos mais recentes foi o caso de um jovem norte-americano, que foi condenado à pena perpétua, por criar boatos e desestabilizar o mercado financeiro.

\section{INTERNET: FÁCIL PARA O SURDO APRENDER}

Um ponto que mostra a vocação natural da Internet para a inserção do surdo, é a possibilidade de se dispor de recursos visuais, como animação de imagens e sinais gráficos, que são de muito fácil compreensão para o surdo, visto que a língua com que se comunicam (a língua de 
sinais) é uma língua espaço-visual. Perguntada sobre como aprendeu a usar o computador, a surda Patrícia responde: Ele próprio me ensina, é muito fácil.

Esta é, com certeza, uma grande vantagem dos surdos. No entanto, nem sempre as interfaces ajudam. Interface é tudo aquilo que nos permite usar o computador para aquilo que desejamos, e que deve facilitar a nossa interação com ele. Assim, se quero imprimir um determinado texto, vou no ícone que tem uma impressora e clico nele. Mas e quando quero salvar algum arquivo? Neste caso, normalmente as instruções são escritas, e com jargões da área. Assim, se já é difícil para ouvintes (iniciantes) entenderem o que têm que fazer, imagine para os surdos, que, em boa parte das vezes, não dominam o Português?! Por conta disso, existem algumas iniciativas, como a de (Pontes e Orth, 1999) que têm tentado desenvolver uma interface própria para os surdos, onde as informações não seriam escritas em Português, mas em Língua de Sinais escrita que será abordada mais a frente, Com isso, acredita-se que a interação do surdo com o computador poderia ser facilitada.

\section{CONVERSA PELA INTERNET}

Por conta de ser um meio multimídia, a Internet é um espaço muito atrativo para o surdo que também a usa com a mesma função do telefone para ouvintes. Isto pode ser percebido por diversos testemunhos dados pelos próprios surdos, que dizem gastar horas em conversas pelo ICQ ou pelo MIRC. Na primeira vez em que eu usei o ICQ, eu entrei às $9 h$ da noite, e só saí às 6h da manhã (Patrícia). Este é o espaço que eles têm de se comunicarem remotamente e em tempo real com quem quiserem, sem a necessidade de intérpretes ouvintes. Com isso, eles podem trocar idéias sobre diversas coisas: língua de sinais, costumes e hábitos dos surdos de outros lugares (inclusive do exterior!), cursos oferecidos na rede,... : Eu conheço surdos de vários locais do Brasil e do mundo: é muito bom! (Patrícia); Uma vez eu estava em um bate-papo conversando normalmente com os ouvintes. Quando disse que eu era surda, eles levaram o maior susto (Regiane).

Este testemunho da Regiane é bastante sintomático, e mostra que as marcas lingüísticas que distanciavam surdos e ouvintes no contexto do português escrito, na Internet desaparecem. Este fato tem começado a despertar o interesse de alguns pesquisadores, mas é fácil de se entender: na Internet, sobretudo no contexto de batepapos, a escrita utilizada pelos internautas tem que ser "rápida". Com isso, ela se torna quase telegráfica, fazendo uso de várias abreviações, e desconsiderando-se, em alguns casos, conectivos e artigos. Além disso, mesmo a ortografia tem sido deixada de lado: como o fluxo das palavras escritas tenta simular o do diálogo falado, não há tempo para floreios, nem para se preocupar com a correção do que se escreve. Tendo-se isto em mente, não é de se estranhar que a presença de surdos nestas "conversas" não seja tão "alienígena".

Além disso, e apesar dos vários vícios presentes no português utilizado nestes meios, a presença do surdo nestes batepapos pode ser vista como um fator motivante para o uso da escrita (em português), para o seu treino e, por que não, para seu estudo. Há uma motivação por trás disso tudo: o surdo (como o ouvinte) quer se comunicar e, para utilizar a Internet, precisa atualmente fazê-lo da forma escrita. Apesar de o português utilizado na rede não ser, em termos da norma culta, o mais correto que se pode ter, para o surdo, esta é uma grande oportunidade para a expansão do seu vocabulário, e para a atribuição de (novos) 
significados aos signos com que está lidando. $\mathrm{E}$ isto também pode ser visto no sentido do letramento...

Seguindo o pensamento de Soares (2000) sobre a definição de alfabetização e letramento, tem-se: letramento é pois, o resultado da ação de ensinar ou de aprender a ler e escrever: o estado ou a condição que adquire um grupo social ou um indivíduo como conseqüência de ter-se apropriado da escrita. Enquanto que alfabetizado é o individuo capaz de ler $e$ escrever. (...) Há, assim uma diferença entre saber ler $e$ escrever -ser alfabetizada- $e$ viver na condição ou estado de quem sabe ler e escrever -ser letrado-. (p 36)

A oposição ouvintes/surdos, ou seja, normatização/deficiência limitou a educação dos surdos num longo período a "falar"/"ler" palavras, necessitando da presença de um leitor ouvinte para significá-las. Consequentemente a produção escrita dos surdos consistia em nomear e descrever ações simples, sem contudo alcançar o estado de letramento. Neste sentido o uso da escrita/leitura na Internet pelos surdos tem lhes proporcionado o letramento, abandonando o estado de alfabetizantes funcionais. No ambiente telemático a comunicação social tem sido ampliada e enriquecida. Através do computador, surdos falantes/leitores de sinais se "apropriaram ${ }^{2}$ da escrita do português. Assim, a Internet desempenha com sucesso o papel que até agora foi delegado à escola, mas sem êxito (referese aqui a uma comunicação escolar que vem deixando de ser veiculada apenas pelas tradicionais tecnologias da lousa, giz e livros).

\footnotetext{
2 Apropriar-se da escrita é tornar a escrita "própria", ou seja, é assumi-la como sua propriedade. (Soares, p 39, 2000)
}

Vale ressaltar que não está em questão no presente trabalho a forma da escrita dos sujeitos surdos, visto que os ouvintes se correspondem nos ambientes telemáticos com uma escrita marcada pela oralidade, e é esperado que os surdos tenham em sua escrita as marcas da língua de sinais, ou seja, a sua "oralidade".

Apesar de o ensino da língua portuguesa ser o grande encalço na educação dos surdos e uma forte razão da evasão escolar, no ambiente telemático os surdos se "apropriaram*' do português transformando-o em instrumento de interação social.

As trocas de experiências no ambiente telemático fazem com que a escrita do português seja significativa. A língua portuguesa tem sido para os surdos, no uso do espaço cibernético, uma segunda língua com função social determinada. Os surdos têm aprendido a desenvolver a escrita e interpretá-la. Por esses leitores estarem inscritos no contexto dos textos dá-se o interesse.

Segundo Alice Freire (98, p 49): "é importante também ressaltar que as dificuldades com os componentes sistêmico podem ser enfrentadas mais naturalmente quando os aprendizes são apresentados a textos escritos que tratam de conhecimento do mundo com o qual eles já estão familiarizados."

A língua escrita tem sido empregada na Internet em situações sociais interativas, com pistas em um contexto imediato, facilitando a compreensão do conteúdo. A língua escrita não decorre da interação face a face em contextos comunicativos onde ambos os interlocutores estão presentes. A idéia da língua escrita vai além disso: ela permite a comunicação sem depender de tempo e lugar. (Svartholm, 98, p 41). 
As oportunidades de escrita e leitura dão aos surdos uma abertura para o mundo da política, cultura, festas, etc. Eles participam do fermento que se dá no mundo. Os surdos têm tido, no ambiente telemático, a oportunidade de dialogar sem opressão das suas características próprias, e compreender quais são os projetos comuns para além da diferença. Este também tem sido espaço de denúncia do fracasso escolar e da falta de educação dos surdos.

No contexto da melhoria no nível do português escrito usado pelos surdos através da utilização da Internet, vale mencionar um estudo feito pelo NIEE (Núcleo de Informática na Educação Especial) da UFRGS (Universidade Federal do Rio Grande do Sul). Neste estudo (Santarosa e Lara, 1996) foi analisado o efeito do uso da ferramenta email por pessoas (jovens e adolescentes) surdas. O e-mail (ou correio eletrônico) é uma ferramenta de trocas de mensagens um pouco mais formal do que os chats (ou bate-papos), com mensagens mais estruturadas, mesmo porque esta não é uma ferramenta para conversa em tempo real. Com isso, além de expandir o vocabulário, o surdo lida com uma estrutura mais formal da língua. Os resultados do estudo mostram, dentre outras coisas: elaboração de mensagens com fatos do cotidiano; utilização de letras maiúsculas no início das frases; utilização correta de pontuação; utilização correta de pronome no início e no meio da frase; elaboração de mensagens com melhora em termos de conteúdo, coerência e logicidade. Além disso, verificou-se: um entendimento mais rápido do conteúdo das mensagens recebidas; maior independência, autonomia e satisfação na comunicação escrita; utilização correta de alguns nexos frasais.
Um outro fator em que a Internet está sendo altamente positiva para o surdo, além da integração entre eles próprios e com os ouvintes, é no sentido de ajudá-lo a conhecer a realidade do mundo que o cerca. Além disso, estão acontecendo alguns fenômenos interessantes, que têm despertado alguns surdos a estudar e ampliar os seus conhecimentos: $\mathrm{Na}$ primeira vez que eu conversei [pelo ICQ] com ela [uma surda da Espanha] eu precisei que uma amiga minha interpretasse. Agora eu comprei um dicionário, e estou aprendendo espanhol (Patrícia). E isto é altamente positivo e dignificante, sobretudo porque é algo que parte deles próprios, e que não está sendo imposto por ninguém: é opção, o surdo seguindo a sua própria vontade.

\section{LÍNGUA DE SINAIS ESCRITA E TRADUTOR ONLINE}

Outro fato interessante, é o crescente interesse pelo sign writing que seria a modalidade escrita da língua de sinais. Percebe-se haver muita confusão, por parte dos surdos que buscam entendê-la, com relação ao que de fato seria isto. Para alguns deles a escrita em sinais seria universal, de modo que todos os surdos do mundo inteiro iriam entender tudo o que estivesse escrito nesta língua. No entanto, a escrita em sinais é um universo de símbolos e convenções, que permite exprimir, com desenho, os gestos que um surdo faz para sinalizar alguma palavra. Estes símbolos e convenções são bastante flexíveis e indicam o ponto de articulação do sinal, o tipo de movimento da mão, a expressão facial e corporal. Eles representam, portanto, os movimentos e expressões realizados pela pessoa, mas um sinal não é necessariamente igual em todas as partes do mundo, nem mesmo em um país. Fazendo uma comparação despretensiosa, estes símbolos gráficos 
estariam para a língua de sinais, assim como as letras estão para as línguas faladas. (Mais detalhes podem ser conseguidos no site LIBRASweb.)

Mas apesar de ainda não se ter um entendimento $100 \%$ correto sobre o que seria a escrita em sinais, este interesse em conhecer, aprender e utilizar esta modalidade da língua deles já revela uma mobilização dos surdos, no sentido de lutar pelos seus direitos. Neste caso, eles estariam buscando entender melhor a multiplicidade de material escrito disponibilizado em rede e que, mesmo para os surdos bem escolarizados, nem sempre é fácil de entender: A gente poderia selecionar o material e utilizar os tradutores [online] para traduzir da língua oral escrita, para a língua de sinais escrita (Patrícia).

No entanto, apesar de potencialmente útil para os surdos, um tradutor online não é,

\section{Texto original}

"No entanto, apesar de However, Tradução para Inglês potencialmente útil para os potentially useful for the deaf útil para os povos surdos, um surdos, um tradutor online people, a translator online is tradutor em linha não está, não é, nos termos da not, in the terms of the nos termos da tecnologia de tecnologia de hoje, tão bom technology of today, so good hoje, assim que por mais boa como seria um bom intérprete as she would be a good que fosse um intérprete bom (da mesma forma como interpreter (in the same way (na mesma maneira que aconteceria, por exemplo, na as he would happen, for aconteceria, para o exemplo, tradução de um texto em example, in the translation of na tradução de um texto no francês para português)." $\quad$ a text in Frenchman for frenchman para o português). Portuguese).

\section{DESMISTIFICANDO O SURDO PARA O OUVINTE}

Além de tudo o que já foi escrito, a presença do surdo na Internet serve como fator desmistificador sobre a sua pessoa, perante os ouvintes. Como já citado de uma fala da Regiane, os ouvintes por vezes although Entretanto, embora potencial

nos termos da tecnologia de hoje, tão bom como seria um bom intérprete (da mesma forma como aconteceria, por exemplo, na tradução de um texto em inglês para português). O problema é que nas línguas existem as expressões idiomáticas, sequências de palavras (ou sinais) que não podem ser entendidas como uma simples justaposição. Isto, assim como o contexto, que pode conferir significados diferentes a um mesmo significante, não é bem considerado quando da tradução feita por máquinas, levando, invariavelmente, a erros por vezes bastante significativos. Um exemplo disso pode ser percebido na tradução (português-inglês) e na versão (inglês-português) apresentadas abaixo, onde se utilizou o Tradutor online do site http://world.altavista.com Como se percebe o texto final é significativamente diferente do original, demonstrando a limitação dos tradutores eletrônicos disponíveis nos dias de hoje.

\section{Retorno para Português}

se assustam em conseguir se comunicar com os surdos, e em perceber que eles podem ser tão capazes como os próprios ouvintes.

Além disso, pessoas e profissionais (professores, fonoaudiólogos,...) interessados em conhecer, entender e lidar melhor com o surdo, podem encontrar referências muito boas na rede WWW. 
Existem vários sites de instituições que trabalham com o surdo (INES Federação Mundial do Surdo, FENEIS, Universidade Galaudet (EUA), entre outros), e existem vários trabalhos de pesquisadores desta área. Para encontrar isto tudo, pode-se usar os chamados sites de busca, como, por exemplo:

- em Portugês: Altavista Cadê. Radix Yahoo

- em Inglês: Altavista Google, Lycos, Northernlight Yahoo

Um exemplo interessante de um trabalho sobre surdez, é o do site LIBRASweb de Simone Aparecida Marcato, que é o resultado de uma tese de mestrado do Instituto de Computação da Unicamp. Este site oferece ao professor (ouvinte) de alunos surdos, ajuda na construção de algumas frases "básicas" para poder se comunicar com pessoas surdas. Isto, além de ajudar na comunicação entre as duas partes, ajuda a aproximar o professor do aluno, uma vez que o primeiro passa a ter menos medo e mais segurança para buscar esta aproximação. Além disso, o site provê várias informações bastante úteis e interessantes sobre a surdez. Vale a pena conferir!

\section{LIMITAÇÕES ATUAIS}

O que se tem hoje, em termos tecnológicos e em nível de Internet, é algo que possibilita ao surdo uma independência quase que total com relação ao ouvinte. Esta é uma característica extremamente positiva para o surdo, uma vez que não precisa mais contar com a boa vontade de um ouvinte, ou ter que se "render" às exigências deste. $\mathrm{O}$ surdo (que pode ter acesso à Internet) começa a ter a possibilidade de se desenvolver de forma mais independente e auto-determinada, seguindo os ditames de sua própria consciência.

Mas apesar disso tudo, o surdo, hoje, só consegue se comunicar pela Internet através de escrita/leitura. Não é possível se comunicar em sinais, uma vez que os recursos visuais, como vídeo-conferências, são muito lentos, e não permitem comunicação em tempo real.

Mas o que o futuro nos reserva?

\section{POTENCIALIDADES DA INTERNET}

\section{EDUCAÇÃO AUXILIADA PELO COMPUTADOR E EDUCAÇÃO VIRTUAL}

Já é uma realidade, desde a década de 1960, o uso do computador no suporte ao processo ensino-aprendizagem. Neste contexto, há aqueles que acreditam na substituição do professor pelo computador, sem perdas para o processo de aprendizado; como também há os que não vêem ganho algum com o uso do computador na "escola". O que se tem percebido desta (longa) discussão, e dos resultados que já foram obtidos, é que o computador, usado como atividade complementar, pode trazer grandes ganhos a este processo. Um exemplo já bastante conhecido é o do uso do software Logo com crianças (ouvintes, surdas, com deficiência mental,...). Este software já mereceu diversos artigos e inúmeras pesquisas. Um local onde se pode encontrar referências sobre o seu uso na Educação Especial, é no NIEE Núcleo de Informática na Educação Especial, da UFRGS).

Atualmente, uma nova forma de uso do computador no processo de ensinoaprendizagem, tem sido a Educação à Distância (EAD). $\mathrm{Na}$ verdade, esta 
modalidade de ensino (dito virtual) remonta sua origem ao final do século XIX, quando era feita através de cartas. No século XX este forma de ensino foi gradualmente incrementada, incorporando os avanços tecnológicos, começando com o rádio, passando à televisão, e chegando ao uso do computador e da Internet/rede WWW. E é exatamente este último avanço (do uso da Internet/rede WWW) que tem sido o foco de diversos estudos e pesquisas nestes últimos anos.

Existem várias vantagens associadas a esta nova modalidade do ensino. Focalizando nas suas potencialidades com relação aos surdos, pode-se citar:

- Como o meio de comunicação usado é o computador, o material pode ser disponibilizado na forma gráfica/escrita, o que facilita o seu entendimento pelos surdos. Além disso, existem iniciativas que apontam para a possibilidade da veiculação destes conteúdos em Língua de Sinais escrita e sinalizada (próxima seção);

- Por ser um curso oferecido pela rede, surdos de diversas partes do país (e do mundo!) podem participar dele (o que diluiria os custos -normalmente elevados- de sua preparação).

- Por ser um curso oferecido pela rede, pode contar com várias de suas facilidades e características. Uma delas, e das mais atraentes, é que, além de os alunos não precisarem estar todos juntos no mesmo local (podem participar do curso quaisquer pessoas que tenham acesso à Internet), eles não precisam, necessariamente, acessar o curso ao mesmo tempo. Assim, se algum surdo trabalha ou estuda (em uma escola presencial!) durante o dia, pode acessar o curso virtual à noite. E esta flexibilidade é extremamente interessante para os dias de hoje, em que sempre temos diversos compromissos.

- Como pode atingir qualquer região que tenha acesso à Internet, este tipo de curso, voltado para a comunidade surda, pode ser organizado por algum centro de excelência, que contaria com professores especializados (e experientes) em trabalhar com surdos, que seriam os encarregados de elaborar $\mathrm{o}$ material a ser ministrado, e de monitorar (e auxiliar) o desenvolvimento dos alunos.

Se estas são apenas algumas das potencialidades do uso desta modalidade de ensino com os surdos, não se podem ignorar alguns problemas a ela relacionados, como:

- Não há, até onde temos conhecimento, estudos sobre o uso do computador no ensino (virtual) de conteúdos programáticos para os surdos. Desta forma, não se sabe se este seria efetivo, nem quais seus possíveis resultados. Além disso, questões como a melhor forma de se mediar um curso deste tipo e a melhor estratégia pedagógica a ser adotada, não estão respondidas nem mesmo para os cursos voltados aos ouvintes.

- Apesar de potencialmente promissora a EAD através da Internet só é possível para pessoas que têm acesso à Internet. Esta, no entanto, não é a realidade da maior parte da população (ouvinte ou surda) do país. Desta forma, ficanos a questão: não existiriam outras modalidades de EAD mais efetivas 
para a nossa realidade (p.e. TV), em que valeria mais a pena investir nosso tempo e nossos recursos?

- Apesar de sua grande abrangência geográfica, um curso através da rede não garante contextualização às diversas realidades cotidianas vividas pelos alunos que dele participam. Além disso, no caso do surdo e de um material disponibilizado em sinais, como se pode garantir que todos eles entenderão o que está sendo exposto, visto que pode haver grandes diferenças entre os sinais de uma região e de outra.

A EAD é um campo que está sendo bastante estudado e explorado hoje em dia. Por isso, apesar de ainda não haver conclusões sobre a sua aplicabilidade (e a forma como deveria ser feita) para os surdos, é preciso que fiquemos atentos para as novidades que podem surgir neste campo.

\section{INTERNET2}

Está em desenvolvimento desde 1996, em um consórcio formado sobretudo por universidades, uma rede ultra rápida de comunicação, que está sendo chamada de Internet2. Esta rede seria bem parecida com a Internet que se tem hoje, com a diferença de ser bem mais veloz. Isto permitiria o uso de vídeo-conferência em tempo real, sem aqueles problemas (muito desconfortáveis) que muitas vezes acontecem hoje em dia: a imagem "emperra"; depois é exibida normalmente por alguns segundos; "emperra" outra vez;.... Com isso, a imagem que se teria seria igual (ou bem parecida) com a de uma televisão normal, sem o desconforto gerado pela variação na velocidade de exibição do vídeo.
Esta rede já está em funcionamento em algumas universidades norte-americanas como a Gallaudet e a Georgetown, que têm aproveitado para ensinar língua de sinais através da Internet. $E$ isto é só o começo, pois as potencialidades desta nova rede são realmente muito grandes.

Imagina se, juntamente com o material escrito disponibilizado nesta página, estivesse também o material visual, com este conteúdo interpretado em sinais. Em termos da tecnologia atual, o tempo que seria necessário para "carregar" este material, ou seja, para copiar este material para o seu próprio computador, seria da ordem de algumas horas. Isto acontece, porque os arquivos de imagem são muito grandes. Para se ter uma idéia, um filminho passando em uma tela de tamanho $5 \mathrm{~cm} \times 5 \mathrm{~cm}$, geraria um arquivo da ordem de 100kbits. Assim, se você estiver acessando esta página da sua casa, um equipamento moderno levaria, hoje, pelo menos $3 \mathrm{~s}$ para carregar somente $1 \mathrm{~s}$ de gravação. Daí vem mais uma constatação acerca da Internet: ela hoje não consegue suportar vídeos (mesmo que exibidos em telas bem pequenas) ao vivo (em tempo real).

Mas se tecnologia utilizada fosse a Internet2, o tempo necessário para carregar este mesmo 1s de vídeo seria bem menor do que 1s. Desta forma, haveria possibilidade de alguém estar sinalizando em frente a uma câmera (ligada a um computador, conectado à Internet), e um surdo o estar vendo, ao vivo, na tela do seu próprio computador (também ligado à Internet).

Internet2 e rede mais veloz não são coisas para daqui há muitos anos, mesmo porque, em alguns lugares (como os Estados Unidos), isto já começa a se tornar realidade. No entanto, fazer previsões para daqui há 50 anos, por exemplo, já é algo 
bem mais difícil. Para se ter uma idéia da dimensão das transformações (e da velocidade com que elas se processam) pelas quais a informática (e o mundo) está passando, basta se lembrar que os primeiros passos na computação eletrônica aconteceram há cerca de 100 anos, e que o primeiro protótipo da Internet (a ARPANET foi implementado há apenas 30 anos.

\section{REALIDADE VIRTUAL}

Algo que está despontando na vanguarda da tecnologia é a realidade virtual (RV), com imagens em três dimensões (3D), que se aproximariam bastante da nossa realidade concreta. A RV apresenta um grande potencial de interação entre as pessoas, e pode fazer uso, além dos recursos audio-visuais a que estamos acostumados, de outros sentidos humanos, como o olfato e o tato.

Existem várias linhas de pesquisa de aplicação da realidade virtual. Uma delas é justamente com pessoas com necessidades específicas. No caso do surdo, como atesta (McLellan, 1996), já foram feitos experimentos e protótipos de ferramentas, onde se tem uma luva com sensores, que deve ser vestida pelo surdo (ou por quem estiver sinalizando), e que permite ao computador "entender" o sinal que está sendo feito, podendo traduzi-lo para a língua oral (escrita ou falada). Além de um dicionário "típico" da língua de sinais própria do país, em algumas destas ferramentas, o computador também é capaz de montar um "vocabulário" próprio do surdo que o usa. Também há a possibilidade de se criarem sinais que poderiam ser a abreviação de uma frase inteira.

Além dessas aplicações específicas, várias das aplicações pensadas para ouvintes podem ser muito úteis também para os surdos. Neste sentido, tem-se:

- Recriacão de ambientes humanamente inalcançáveis, como a superfície de outros planetas, o fundo do mar, ou a cratera de um vulcão em erupção.

- Recriação de ambientes que já existiram, como o mundo da época dos dinossauros, o Senado romano da época de Sêneca, a sociedade egípcia do tempo de Ramsés II,...

- A criação de comunidades virtuais onde a interação não se daria somente através de vídeo e/ou da escrita, mas que poderia ser quase tão realista quanto se conseguisse (através do tato, do olfato,...).

O que se percebe é o grande potencial pedagógico e integrador desta nova realidade. Várias pesquisas estão em curso, e muitas outras ainda são necessárias para, de fato, poder-se fazer uso da potencialidades que esta nova tecnologia parece oferecer.

\section{FINALIZANDO SEM CONCLUIR}

A Internet está revolucionando a vida de milhões de pessoas no mundo inteiro, sejam elas ouvintes ou surdas. A dimensão destas mudanças é variável, e depende da realidade em que se vive, e daquilo que se busca (ou pode ser encontrado) através da rede.

No caso dos surdos, a Internet tem se mostrado como um forte fator de agregação das diversas comunidades espalhadas pelo país e pelo mundo. Além disso, abrem-se as portas para uma maior interação com os surdos de outros locais (dentro e fora do país), o que é extremamente positivo. 
A Internet está trazendo consigo a possibilidade de os surdos se unirem e de lutarem pelos seus direitos. Além disso, ela mesma oferece aos surdos subsídios para que eles conheçam e interajam na realidade sócio-político-cultural de seu meio. E estes subsídios, hoje restritos a materiais escritos, podem, em um futuro próximo, estar disponíveis na própria língua dos surdos, o que poderia aumentar muito o seu entendimento por eles.

Mas a interação com o ouvinte, apesar de possível, é muito menos valorizada do que a interação com outros surdos. Isto é democracia, é direito de escolher com quem "conversar". Além disso, existem fatores que alguns chamam de "identificação 剚: assim como a maioria dos ouvintes se "identificam" com outros ouvintes, a maioria dos surdos se "identificam" com outros surdos. E isto parece ser o caminho natural das coisas: a criação de micromundos de "iguais", com fronteiras mais ou menos fortes dependendo dos fatores culturais de seus membros, e da tensão com os outros mundos.

Ao que nos parece, no entanto, se isto pode trazer contribuições muito positivas para a dignidade do surdo, pode também aumentar o fosso entre as comunidades de surdos e a comunidade de ouvintes onde ela está "inscrita". Por isso, é preciso muito cuidado, mesmo da parte dos teóricos ouvintes que estudam a surdez, no

3 Identificação: segundo o dicionário online Michaelis, é ação ou efeito de identificar ou identificar-se. Por sua vez, identificar seria: "3 Tornar-se idêntico a outrem, assimilando-lhe as idéias e os sentimentos; adquirir a índole ou natureza de outro: "...pela transformação, transformando-se em Deus; pela identidade, identificando-se com Ele" (Pe. Antônio Vieira). vpr 4 Conformar-se, ajustar-se: Identificar-se com o ambiente." sentido de oferecer ao surdo tudo o que possa lhe trazer dignidade e equidade com o ouvinte, sem, no entanto, fomentar o aumento da distância entre estes dois mundos. Além disso, deve-se respeitar a vontade do surdo que, por princípios éticos, deve ter a liberdade de escolher integrar-se a uma comunidade surda, a uma ouvinte ou a ambas.

A Internet tem o potencial extremamente alto de promover a integração entre os seres humanos, e esta é uma característica extremamente importante, pois permite a criação de laços entre as pessoas, e a superação de vários PRE-conceitos e injustiças. No entanto, se os meios evoluíram tanto, a ponto de se ter, nos dias de hoje uma ferramenta tão poderosa como é a Internet e a rede WWW, a consciência da humanidade ainda está a anos-luz de distância. Neste mesmo mundo, apesar da tecnologia e da riqueza de uns (poucos), muitos ainda morrem de fome, frio e sede.

Por isso, é preciso que a consciência do homem também evolua. Neste sentido, a Internet pode ser extremamente útil, para promover a aproximação entre pessoas, e o contato com realidades distintas.

\section{E como fazer isto?}

É opção de cada um de nós, que fazemos (mesmo inconscientemente) a cada dia que nasce...

\section{SITES}

Alguns sites no Brasil sobre o surdo:

- Internet e Surdos: Possibilidades Infinitas de Comunicação Site de Rossana Delmar de Lima Arcoverde e Eleny Gianini, da UFPB (Universidade Federal da Paraíba). 
- FENEIS Federação Nacional de Educação e Integração do Surdo.

- INES Instituto Nacional de Educação do Surdo.

- LIBRASweb site de Simone Aparecida Marcato, onde se tem informações sobre a língua de sinais (escrita e sinalizada); e onde um intérprete surdo sinaliza algumas frases e palavras "básicas" para a comunicação com um surdo.

- EDUSURDOS Rede como Apoio à Interação, Construção e Troca de Informações sobre a Educação de Surdos.

- Éfeta Pastoral do Surdo da Igreja Católica de Campinas.

Páginas Pessoais de Surdos:

- Marcelo Amorim

- Fabiano Rosa

- Otávio B. de Lorenzo.

Sites estrangeiros sobre o surdo:

- Internet Resources in Sign Language Interpreting \& Deafness

- Deafness Related Issues.

- Deaf Education Web Site

- World Federation of the Deaf. Federação Mundial do Surdo.

\section{REFERÊECIAS:}

COM TODOS OS SENTIDOS - São Paulo. Revista do Ensino Superior - ano 2, no. 19 , março de 2000.
Deaf History Page, Disponível na World Wide Web:

< http://www.atkosoft.com/deafhist.htm> [capturado em: julho de 2000]

Encontro Nacional de Surdos que se Conheceram na Internet, 17/06/2000, São Paulo FENEIS.

Entrevista/apresentação feita com as surdas Patricia Hipolito de Alexandria Silva Nunes e Regiane Pinheiro Agrella, no dia 8 de agosto de 2000, na Faculdade de Educação da Unicamp.

FREIRE, A. Aquisição de Português como segunda língua: uma proposta de currículo. Rio de Janeiro. Revista Espaço/INES junho/98. P.46-52.

GOLDFELD, M. A Criança Surda Linguagem e Cognição numa perspectiva sócio-interacionista. Editora: Plexus, 1997.

History Through DEAF EYES a social history exhibition - Gallaudet University.

Disponível na World Wide

Web:http://www.gallaudet.edu/ deafeyes/ [capturado em: julho de 2000]

HOWE, W., A Brief History of the Internet, 2000. Disponível na World Wide Web:

$<$ http://www0.delphi.com/navnet/history.h tml> [capturado em: julho de 2000]

JONE, Telecommunications \& Multimedia Encyclopedia, Computers: History and Development Disponível na World Wide Web: $<$

http://www.digitalcentury.com/encyclo/up date/comp_hd.html> [capturado em: julho de 2000]

LANE, H. A Máscara da Benevolência:

A comunidade surda amordaçada. Lisboa. Instituto Piaget, 1992. 
LURILLARD, D. The Changing University, 1996. Disponível na rede WWW no endereço: $<$ http://itech1.coe.uga.edu/itforum/paper13 /paper13.html> [capturado em: janeiro de 2001]

MCLELLAN, H. Vitual Realities. Handbook of Research for Educational Communications and TECHNOLOGY Cap. 15 - New York, 1996.

MONTEIRO, P. Com todos os sentidos. Revista Ensino Superior. Ano 2, no. 19, março de 2000.

PONTES, A. M. e Orth, A. I. Uma proposta de interface de software orientada à linguagem de sinais, 1999.

REVISTA DA FENEIS. Ano I, números (janeiro/março de 1999) e 2 (abril/junho de 1999); Ano II, números 6 (abril/junho de 2000) e 8 (outubro/dezembro de 2000). Rio de Janeiro.

SÁ, N. R. L. Educação de Surdos: A caminho do Bilinguismo. Niterói. Editora: EdUFF, 1999.

SACKS, O. Vendo Vozes: Uma jornada pelo mundo dos surdos. Editora: Companhia de Letras, 1989.

SANTAROSA, L. M. C. e Lara, A. T. S. (online) Telemática: um novo canal de comunicação para deficientes auditivos., RIBIE 1996. Disponível na World Wide Web através do NIEE $<$ http://www.niee.ufrgs.br/>.
SOARES, M. Letramento: Um Tema em Três Gêneros. Belo Horizonte. Editora: Autêntica, 2000 - $2^{\circ}$ edição.

SVARTHOLM, K. Aquisição de segunda língua por surdos. Rio de Janeiro. Revista Espaço/INES junho/98. P.38-45.

TANENBAUM, A. S., Computer Networks - Third Edition, Prentice Hall, 1996.

VALENTINI, C. B. As novas tecnologias da informação e a educação de surdos. In: SKLIAR,C (org.). Atualidade da educação bilíngüe para surdos. Porto Alegre. Editora: Mediação, 1999.

Andréa da Silva Rosa

Diretora de Educação e Cultura da ASSUCAMP Pedagoga/Intérprete de Língua de Sinais andrearosas@zipmail.com.br Cristiano Cordeiro Cruz Mestrando em Educação para Engenharia UNICAMP

Engenheiro Eletricista/Intérprete de Língua de Sinais cristia@decom.fee.unicamp.bo 